\title{
J95 Health Surveillance in Multinational Division South West (Bosnia): July - November 1996
}

Maj JP Owen

MB, ChB,MMedSc,MFOM,RAMC

Col AHM Macmillan

MB,ChB,MPH,MFPHM, late RAMC

Medical Branch, $H Q 1$ (UK) Armd Div, BFPO 15

SUMMARY: A modified version of the $\mathbf{J 9 5}$ morbidity reporting system, called J95a, was used in the Multinational Division South West (MND SW) during Operation Resolute 2. The broad scope of the 'Other Diseases' and 'Other Injuries' event codes were reduced, with codes being added for specific areas of interest which were 'ENT Problems 'Sports Injuries' and 'Training Injuries'. Designated medical centres from all nations in the division reported on $\mathbb{Q}$ monthly basis to HQ MND SW, enabling the morbidity profile to be monitored. The first attendance rates in MND SW were twice as high as those experienced by the whole of the British Army, though the rate of working days lo was only a third. Almost half $(\mathbf{4 9 \%})$ of the working time lost in the division was due to injuries and orthopaedic problems. The disease and injury distribution showed considerable differences compared to the SHAPE plannin figures, with the disease rates experienced being between half and two thirds of those predicted, whilst the injur rates experienced were between four and six times as high as those predicted. This evidence suggests that the planning figures need to be re-assessed for operations other than war. Further investigation into the aetiology of injuries causing loss of working time is recommended, particularly sports injuries and orthopaedic problems.

\section{Introduction}

The J95 morbidity reporting system was introduced into the Army on 1 Jan 96, having been designed and trialled for use in both operational and non-operational settings (1). The system enables data to be collected regularly on the number and type of attendances made by personnel to their primary care medical centre or their medical officer. Both the rate of morbid events and their impact on the military work force, measured in terms of 'Working Days Lost', can be assessed. This provides valuable information for medical resources allocation and briefing of commanders. Comment has been made that the J95 classification is too coarse with $63 \%$ of all attendances being recorded in the overflow categories of 'Other Disease', or 'Other Injury' (2). However, the J95 system has been designed to allow modification and development over time and for different circumstances, both operational and non-operational. This can only happen once data has accumulated to indicate which events need expanding and which ones can be amalgamated.

Following the signing of the Dayton peace agreement NATO deployed an implementation force (IFOR) of approximately 50,000 personnel to the Former Republic of Yugoslavia and an operational variant of the J95 reporting system was adopted for use. Within the MND SW the J95 system was further modified from July 1996, being designated J95a. This system enabled data to be collected in a standardised format from all nationalities in the division, for reporting to IFOR, and in addition enabled extra detail to be monitored in several areas of interest. The modifications consisted of amalgamating the 'Peptic ulcer' event code in with 'Other diseases of the digestive system', removing the 'NBC indicators' narrowing the scope for 'Other Diseases' by addin separate field for 'ENT disorders'. The 'Other Injuffess category was also refined by creating separate fieldsfor 'Training Injuries' and 'Sports Injuries', in order to as\&s\$. the relative impact of these activities on medical attendance and working time lost.

The aim of this paper is to present the J95a data on the disease and injury profile within MND SW over the period July - November 1996.

\section{Methodology}

The principal primary care practices within MND S were identified. The spread of these designated practice ensured that the total military population was accounted for within the area of operations. In some cases thes principal practice had one or more subsidiary medica centres under administrative control. Each designate

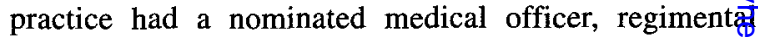
nursing officer or medical support officer responsible for the J95a data collection from the practice and any subsunits.

Each month every practice completed a J95a reporting sheet, recording the main reason for attendance for each medical problem related attendance for all military. patients. The event codes recorded are shown in Table P. Screening examinations, PULHHEEMS and vaccination were excluded, unless specific pathology was uncoveref: Details were also recorded of the type of attendances. (initial or follow up) and outcome (light duties, beddend down, referred to an outpatient facility or directho admitted to a secondary care facility). At the end of each month each designated practice collated the reporting 
Table 1. J95a Event Codes

\begin{tabular}{|c|c|c|c|}
\hline Abbreviation & Full Event Code & Definition & DNBI Group \\
\hline Int Inf Dis & Intestinal Infection & All infections of the gut. & Disease \\
\hline STD & Syphilis and STD & All forms of sexually transmitted disease & Disease \\
\hline Other Inf & Other Infectious Diseases & All infectious diseases not elsewhere classified & Disease \\
\hline Alc/Drug & Alcohol and Drugs & $\begin{array}{l}\text { Alcohol or drug dependence syndromes, non-dependent abuse of alcohol } \\
\text { or drugs. }\end{array}$ & Disease \\
\hline Mental Dis & Mental Disorders & Behavioural changes and distrubance of normal conduct. & Disease \\
\hline Stress R. & Stress Reactions & $\begin{array}{l}\text { Reactions to stress, including Post Traumatic Stress Disorder and } \\
\text { Adjustment Disorders }\end{array}$ & Disease \\
\hline Eye Dis & Eye Disorders & Disorders of the eye and its surrounding structures. & Disease \\
\hline Asthma & Asthma & Asthma due to all causes. & Disease \\
\hline Other Resp Dis & Respiratory Disease & Disorders of the respiratory system, excluding asthma. & Disease \\
\hline Oral Dis & Oral Cavity & All diseases and disorders of the mouth and teeth. & Disease \\
\hline Dig Sys Dis & Digestive Disease & Diseases of the digestive system, liver, pancreas and gall bladder & Disease \\
\hline Contr/Gynae & $\begin{array}{l}\text { Gynaecology, Pregnancy } \\
\text { and Contraception }\end{array}$ & $\begin{array}{l}\text { Contraception, all diseases of the female reproductive system and } \\
\text { complications of pregnancy }\end{array}$ & Disease \\
\hline Derm Probs & Dermatology Problems & Diseases of the skin and subcutaneous tissue. & Disease \\
\hline Knee/Jnt & $\begin{array}{l}\text { Internal Derangement of the } \\
\text { Knee and Joint }\end{array}$ & All derangements of the knee and joint. & Disease \\
\hline Dorsopath & Dorsopathies & Spine, disc, neck and unspecified back disorders. & Disease \\
\hline Other MS & $\begin{array}{l}\text { Other Musculo-Skeletal } \\
\text { Diseases }\end{array}$ & $\begin{array}{l}\text { Joint and related structure disease, excluding back and acquired } \\
\text { deformities }\end{array}$ & Disease \\
\hline RTA Inj & Road Traffic Accident Injuries & All injuries when due to road traffic accidents. & $\mathrm{NBI}$ \\
\hline Other NBI & Other Injuries & $\begin{array}{l}\text { All injuries not elsewhere classified (excludes those caused by war, } \\
\text { RTA's, sports and training). }\end{array}$ & NBI \\
\hline War Inj & War Injuries & All injuries caused by operations and war. & BI \\
\hline Heat/Cold & Heat and Cold & $\begin{array}{l}\text { Climatic injuries, including heat stroke, heat illness, non-freezing } \\
\text { cold injury and frostbite. }\end{array}$ & NBI \\
\hline Iatrogenic & Iatrogenic Illness & Complications of medical care. & NBI \\
\hline Other Dis & Other Disease & All diseases and symptoms not elsewhere classified. & Disease \\
\hline ENT & Ear Nose and Throat Problems & All disorders of the ear, nose and throat. & Disease \\
\hline $\operatorname{Trg}$ Inj & Training Injuries & $\begin{array}{l}\text { Injuries from formal military training, including BFT, CFT, adv trg and } \\
\text { squadded road work. }\end{array}$ & NBI \\
\hline Sport Inj & Sports Injuries & $\begin{array}{l}\text { Injuries from sporting activities (individual or group) outside formal } \\
\text { military training. }\end{array}$ & NBI \\
\hline
\end{tabular}

sheets for their unit and any sub-units before passing the data to HQ MND SW for analysis.

At HQ MND SW the data were checked for completeness and accuracy, using the divisional G1 personnel reports (PERSREP) to verify the denominator. Analysis was then carried out using the EpiInfo Statistics package and Microsoft Excel software. The incidence rate for the events recorded was expressed as the number of first attendances per thousand personnel per month (/1000/month), while the impact of manpower loss on the work force was expressed at the rate of working days lost. The overall Disease, Battle and Non-Battle Injury (DNBI) rates were also expressed as percent per day (/100/day) of the work force.

\section{Results}

Twenty one reporting medical centres were identified and throughout the reporting period compliance remained over $90 \%$. For the last month there were only 19 reporting practices due to the closure of two of the

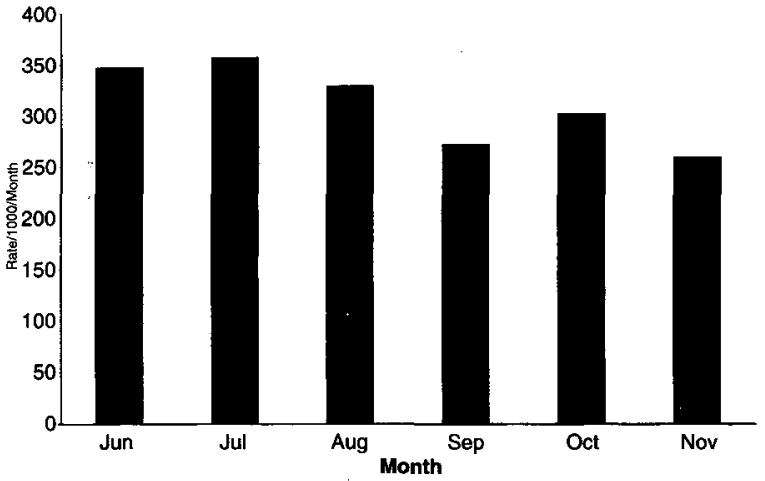

Fig 1. Rate of First Attendances for All Causes in MND SW

medical centres.

The monthly first attendance rate, at Figure 1, shows an overall decrease over the period of Operation Resolute 
2 , though there were slight increases in July and August. The rate of working days lost for all causes is shown at Figure 2, where the pattern of increased rates in the second and fifth month is repeated. There is no corresponding decrease in the rate of working days lost over the duration of Operation Resolute 2 when compared to the rate of first attendances.

The events causing the attendances at the medical centres are shown at Figure 3. The mean monthly first attendance rate was 311/1000/month. The main diseases recorded were 'Dermatological Conditions' (53.8/1000/month), 'Respiratory Disease' (34.9/1000/ month), 'Other Musculo-Skeletal Conditions' (25.9/1000/ month) and 'ENT Problems' (23.0/1000/month). The main injuries were 'Other Injuries' (54.5/1000/month) with 'Sports Injuries' (13.6/1000/month) and 'Training Injuries'

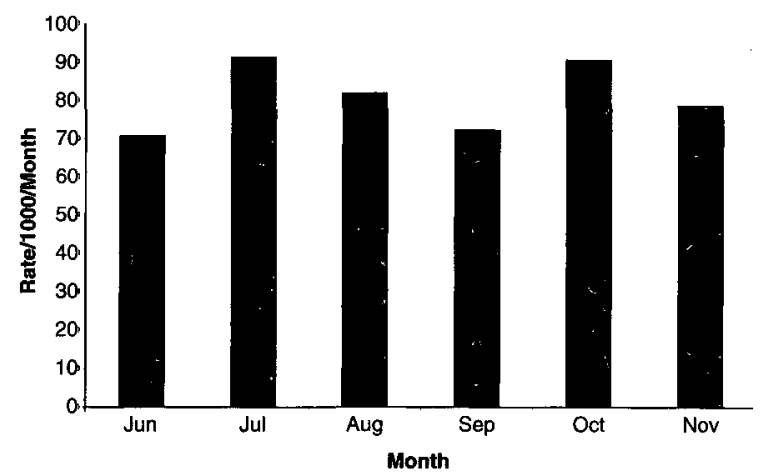

Fig 2. Rate of Working Days Lost for All Causes in MND SW

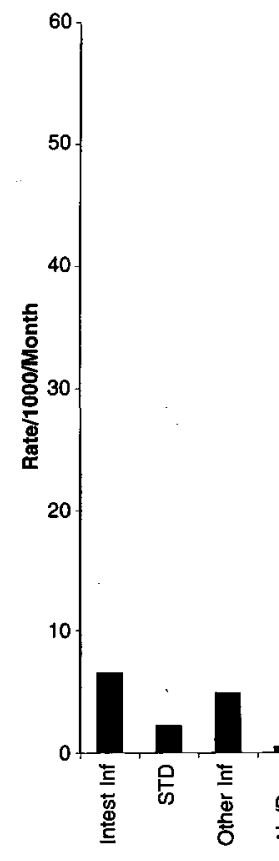

J95 Health Surveillance Bosnic冖.

(3.7/1000/month) at a lesser frequency.

The impact of these diseases and injuries on th $\overline{0}$ efficiency of the work force is reflected in the rate of working days lost for each event which is shown at Figure 4. The mean monthly rate of working days lost for a events was $81 / 1000 /$ month.

The relatively small impact of time off work fos? dermatological problems (3.7/1000/month) can be seere compared to events such as 'Respiratory Disease' where. time off work was more common $(7.3 / 1000 / \text { month })^{n}$. Orthopaedic problems can be seen to be a major caus $\$$. working days lost, particularly with the groups of 'Otheses Injuries' (13.9/1000/month), 'Other Musculo-SkeletalConditions' (13.6/1000/month) and 'Sports Injuries. $(12.2 / 1000 /$ month). These three events accounted for almost half $(49 \%)$ of all the working days lost during the study period.

The DNBI rates experienced compared to the predicte figures are shown at Figure 5. The SHAPE planning figures (3) were set at $1.35 / 100 /$ day for Disease $0.05 / 100 /$ day for Non-Battle Injuries and $0.1 / 100 /$ day foP Battle Injuries. The actual incidence rates experienced (First Attendances) were significantly different, with the average disease rate ranging from $0.66-0.93 / 100 /$ day an ${ }^{2}$ the average NBI rate ranging from $0.20-0.34 / 100 / \mathrm{d} \overrightarrow{\mathrm{y}}_{\mathrm{T}}$. The rate of working days lost for NBI reached a maximitip in August $(0.157 / 100 /$ day) more than twice the not experienced in November $(0.07 / 100 /$ day). The total raes. of working days lost, for all causes, ranged from 0.7 $0.30 / 100 /$ day and are shown at Figure 6 . 


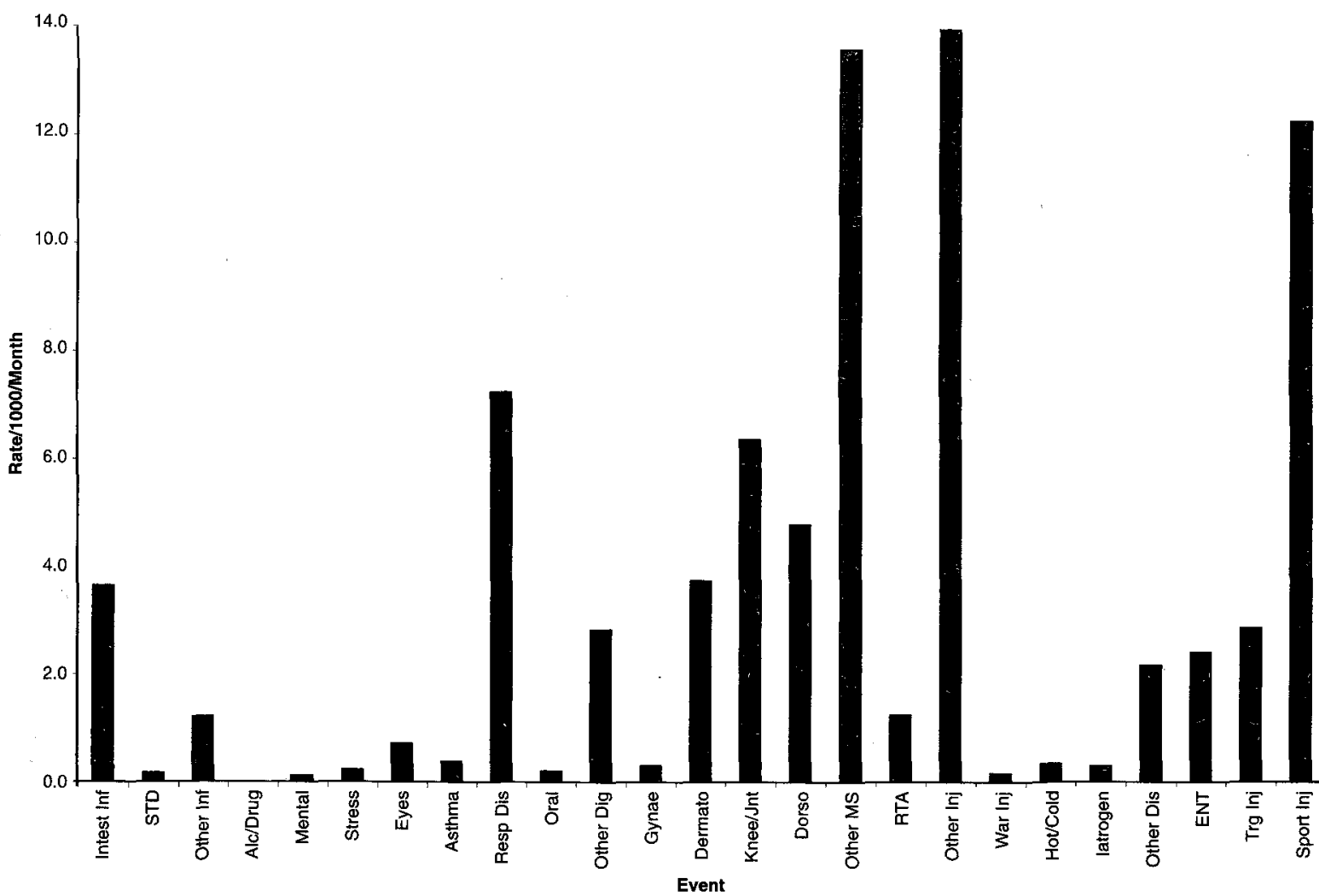

Fig 4. Rate of Working Days Lost in MND SW (June - Nov 96)

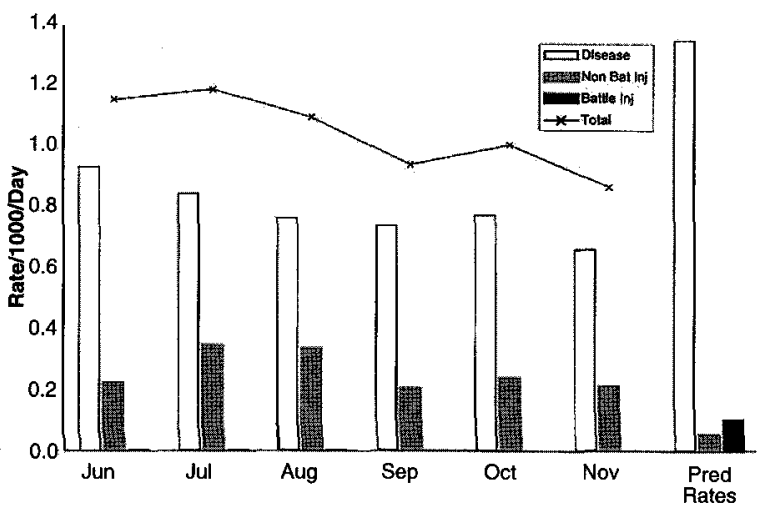

Fig 5. Predicted vs Actual DNBI Rates for MND SW

\section{Discussion}

The deployment of personnel on operations other than war (OOTW) presents different problems to those experienced in conventional warfighting. The aetiology, pathology and management regimes for medical problems also varies according to the type of operations being undertaken. Under the OOTW conditions experienced during Operation Resolute 2 most personnel were accommodated in semi-permanent locations with close access to support services, including medical care.

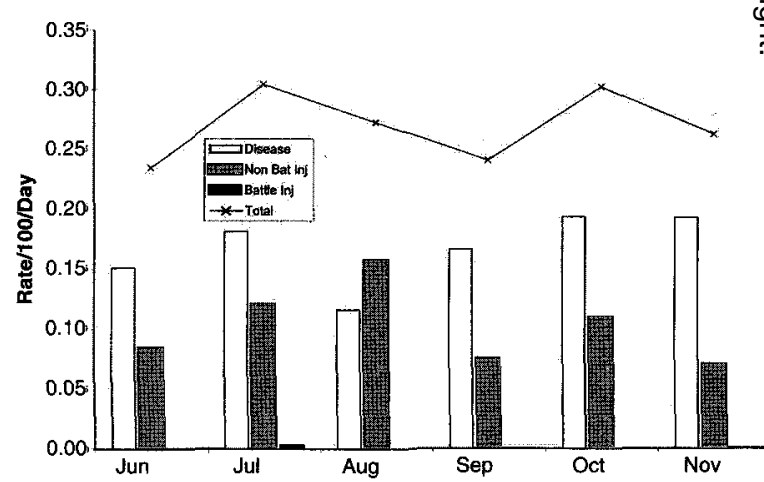

Fig 6. DNBI Rates experienced for Working Days Lost in MND SW

The first attendance rate experienced in MND SW was twice as high as that experienced by the Army as a whole (Army first attendance rate for $1996=151 / 1000 /$ month), though the rate of working days lost was less than a third of that for the Army (297/1000/month) as reported in the J95 Annual Report for 1996 (4).

There are a number of reasons for these differences; in the case of the medical attendances, the increase within MND SW may well reflect the inability for individuals to treat themselves with 'Over the Counter' medications. 
This is reflected in the high attendance rate but low rate of working days lost for dermatology problems. Anecdotal evidence from the medical centres indicated that the majority of these presentations were for minor medical complaints such as athletes foot and other fungal skin infections which are a common feature of an operational deployment to a Mediterranean climate in the summer months.

The rate of working days lost in MND SW were a third of that for the rest of the Army. However, the Army rates are distorted by the high injury rates in the Training Establishments, as shown in the J95 Annual Report. Within MND SW injuries accounted for half of the working days lost in the primary care settings. It is of interest that there was an increase in the rate of working days lost in the months of July and October, within a month of the roulements which took place in June and September. This supports the hypothesis that there is an increased injury and illness rate amongst the units newly deployed into theatre.

Health data collected during the first six months of Operation Resolute (5) revealed a slightly higher rate for disease, which ranged from $0.73-1.92 / 100 /$ day and also for NBIs, which ranged from $0.29-0.59 / 100 /$ day. This may be due to climatic difference from winter to summer or the increased knowledge of local conditions that was available to be passed on to the division over the second six month period.

The DNBI rates from both the deployment periods do not match the SHAPE predictions, casting some doubt on their validity in OOTW. Over the second six months the disease rate varied between half to two thirds of the predicted rate, the NBI rate was between four and six times greater than that predicted and the Battle Injury rate remained negligible. The accumulating evidence of actual DNBI rates from Bosnia indicate that there is a need for a further set of casualty planning figures for use in OOTW.

The J95a system allows for broad categorisations of the morbid events, helping to focus attention on areas of interest and demonstrating the magnitude of the problem in terms of lost productivity. The modifications incorporated into J95a show that ENT problems make up over half of the attendances which were previously classified as 'Other Disease'. They also demonstrate that training injuries and sports injuries account for over half $(52 \%)$ of the working time lost from what was previously classified as 'Other Injuries' in the J95 system. However, further examination is still required in order to ascertain the aetiology of these morbid events in sufficient detail to change working practices. Within MND SW the areas of concern for loss of working days were principally related to orthopaedic problems ('Sporting Injuries', 'Other Injuries', 'Other Musculo-skeletal Diseases' and 'Internal Derangement of the Knee and Joint'). The only other event causing notable loss of working time in the primary care setting was 'Respiratory Disease'.

Anecdotal evidence from the MND SW area indicated that many of the camps were able to provide a reasonable selection of indoor fitness training equipment. However, the outdoor sports and training areas were usually rudimentary, with units making use of spare groundo within the camp, whilst off-camp training was limited to road-running along checked routes. There is no dispute; that military personnel need to maintain high levels ofs physical fitness, however, the injuries incurred duringo training which prevent an individual from workingo negate the benefits of improved fitness. Therefore units need to ensure that the physical training is carried out in a safe manner, whether individually or as organisedo groups, with possible restrictions on some sports such as? football, as recommended in previous study during the first six months of Operation Resolute (6).

The J95a reporting system was used by all theo nationalities within MND SW, including Canadian Dutch and Malaysian contingents. The system has been? shown to provide valid data in the multinational setting, though close supervision is required to ensure returns are $\overrightarrow{+}$ accurate and on time. The normal J95 system should beo modified to include some of the J95a changes' successfully piloted in Bosnia; in particular sports and training injuries classifications should be included, in? order to reduce the scope of the 'Other Injuries' eveft code, and an ENT classification to reduce the scope of 'Other Diseases' event code.

Within NATO, a morbidity reporting system designated as EPINATO, is planned based on the 195 model. As the case with J95, it is anticipated that EPINATO system will develop in time to reflect 速e requirements of each theatre of operations.

\section{Conclusion}

The $\mathrm{J} 95$ reporting system was taken up by all the designated medical centres in MND SW and provided $\frac{D}{D}$. comprehensive profile of the morbidity pattern within the division. Analysis of the data indicated that actual DNBB rates on OOTW differ significantly from those used for planning purposes. It is suggested, therefore, that ap revised set of DNBI planning parameters are used for peace keeping operations.

The burden of pathology experienced was related to injuries and orthopaedic problems, which accounted for half of the working time lost in the division. It iso recommended that the event codes trialled in J95a are included in the normal $\mathrm{J} 95$ reporting system, in particular the extraction of sport and training injuries from the 'Other Injuries' event code and the extraction of ENTO problems from 'Other Diseases' event code. Having highlighted the magnitude of the loss of working times associated with sports and other injuries, it is also ${ }^{\mathrm{D}}$. recommended that attention should be given to assessing how the injuries can be prevented.

\section{REFERENCES}

1. JefFERSON TO, Demicheli $V$, MaCMillan AHMc Pilot study of the introduction of the J95 health data 
collection system. J R Army Med Corps 1996; 142: 25-29.

2. LEACH AJ. J95 Health data collection system. $J R$ Army Med Corps 1996; 142: 85-86.

3. ACE Medical Support: Principles, Policies and Planning Parameters. ACE Directive 85-8 dated 26 October 1993.

4. J95 Annual Report 1996. Army Medical Directorate.
D/AMD/505/1/3 dated 30 Jan 97.

5. Croft AMJ, Creamer IS. Health Data from Operation Resolute (Bosnia). J R Army Med Corps 1997; 143: 13-18.

6. ADAMS MS, CROFT AMJ. Sports injuries in British Troops deployed on Operation Resolute (Bosnia). $J R$ Army Med Corps 1997; 143: 35-38. 